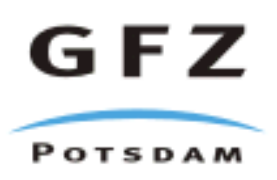

Originally published as:

di Primio, R., Neumann, V. (2007): HPHT reservoir evolution: a case study from Jade and Judy fields, Central Graben, UK North Sea. - International Journal of Earth Sciences, 97, 5, 1101-1114

DOI: 10.1007/s00531-007-0206-y. 


\section{HPHT Reservoir Evolution: A Case Study from Jade and Judy Fields, Central Graben, UK North Sea}

ROLANDO DI PRIMIO

VOLKMAR NEUMANN

GFZ-Potsdam, Telegrafenberg, 14473 Potsdam, Germany

dipri@gfz-potsdam.de

$+493312881786$

$+493312881782$

Keywords: North Sea; High pressure - high temperature (HPHT); 3D basin modelling; compositional modelling of hydrocarbon generation

\section{Abstract}

3D basin modelling of a study area in Quadrant 30, UK North Sea was performed in order to elucidate the burial, thermal, pressure and hydrocarbon generation, migration and accumulation history in the Jurassic and Triassic high-pressure high-temperature sequences. Calibration data, including reservoir temperatures, pressures, petroleum compositional data, vitrinite reflectance profiles and published fluid inclusion data were used to constrain model predictions. The comparison of different pressure generating processes indicated that only when gas generation is taken into account as a pressure generating mechanism, both the predicted present day as well as palaeo-pressure evolution matches the available calibration data. Compositional modelling of hydrocarbon generation, migration and accumulation also reproduced present and palaeo bulk fluid properties such as the reservoir fluid gas to oil ratios. The reconstruction of the filling histories of both reservoirs indicates that both were first charged around $100 \mathrm{Ma}$ ago and contained initially a two phase system in which gas dominated volumetrically. Upon burial reservoir fluid composition evolved to higher GORs and became undersaturated as a function of increasing pore pressure up to the present day situation. Our results indicate that gas compositions must be taken into account when calculating the volumetric effect of gas generation on overpressure. 


\section{Introduction}

High pressure - high temperature (HPHT) reservoirs are increasingly becoming the focus of petroleum exploration in the search for additional reserves. The processes leading to the accumulation and preservation of hydrocarbons in these extreme settings are still poorly constrained, especially also with respect to the occurrence of significant porosity at temperatures exceeding $150^{\circ} \mathrm{C}$ and pressures approaching lithostatic. The processes controlling the evolution of fluid pressure during reservoir burial have been studied by various authors. Overpressure generating mechanisms have been reviewed by Osborne and Swarbrick (1997), who postulated that disequilibrium compaction is the main mechanism controlling overpressure in the Central Graben. This opinion is supported also by Mann and Mackenzie (1990), although the importance of additional overpressure generation due to gas generation is becoming increasingly acknowledged (Cayley, 1986, Isaksen, 2004, Swarbrick, et al., 2000). One deficit of previous modelling approaches is that they rarely, if at all, are capable of comparing the effects and contribution of individual processes to the cumulative overpressure generated.

Predicting hydrocarbon compositions in HPHT reservoirs is also fraught with problems. Hydrocarbon generation has been studied in detail by various laboratory methods. While bulk kinetic characterisations of the response of organic matter to thermal stress are well established (Tissot and Espitalie, 1975), compositional kinetic models describing the generation of gas and liquid hydrocarbons have only recently become available (Behar, et al., 1992, di Primio and Skeie, 2004, Dieckmann, et al., 1998, Espitalie, et al., 1988). These latter kinetic models describe the primary generation of individual components or component classes and their secondary transformations upon increasing thermal stress. While bulk kinetics and compositional predictions from primary cracking have proven their applicability (Schenk, et al., 1997, Schenk and Horsfield, 1993), demonstrating the correctness of secondary cracking predictions has been problematic (Vandenbroucke, et al., 1999). For example the stability of liquid petroleum in reservoirs seems to be relatively high (Horsfield, et al., 1992, Schenk, et al., 1997), indicating that it can withstand temperatures close to $200^{\circ} \mathrm{C}$ under geologic heating rates, whereas in source rocks residual oil is converted to gas at lower levels of thermal stress (Dieckmann, et al., 1998). As stated above, compositional predictions from kinetic models in combination with basin models have as yet large difficulties in correctly predicting the fluid composition and phase in deep, hot reservoirs (Vandenbroucke, et al., 1999), although newer models calibrated to observed fluid properties indicate that good 
predictions regarding the gas to oil ratio (GOR) and even phase properties are possible for the realm of primary cracking (di Primio and Horsfield, 2006, di Primio and Skeie, 2004). The comparatively common occurrence of severely undersaturated, light oils or wet gascondensates is typical of HPHT reservoirs in the deep Central Graben. Based on bulk kinetic or compositional kinetic models these hydrocarbon compositions are virtually impossible to explain, as conventional kinetic predictions indicate that essentially only dry gas should be generated from the source rocks under these conditions (e.g. Dieckmann, et al., 1998, Wendebourg, 2000).

The goals of this study were, hence, to investigate both overpressure generation and hydrocarbon compositional evolution in an HPHT setting of the Central Graben, namely the Jade and Judy fields in Quadrant 30, UK North Sea, using 3D basin modelling.

\section{Geological Setting}

The North Sea, and in particular the Graben system is one of the world's major hydrocarbon provinces. The North Sea Central Graben is the northwest-southeast-trending southern extension of a three-arm rift system, consisting of the north-northeast to south-southwest trending Viking Graben as the northern component, the northwest-southeast trending Inner and Outer Moray Firth with its component, the Witch Ground Graben as its western part, and the Central Graben, the latter being subdivided into the West Central Graben and the East Central Graben, separated by the Forties-Montrose horst block, and flanked by marginal platform areas. Despite the technical challenge of exploring for HPHT fields, activity has moved more and more in this direction, for example in the HPHT regions located around the British Block 30, where temperatures exceed the limits of $150^{\circ} \mathrm{C}$. Due to the long exploitation history, the geologic and tectonic settings are well known. A detailed compilation is given in Glennie (1998), the following section summarizes the geologic evolution of the Central Graben.

At least two major rifting phases, one during the Permo-Triassic (290-210 Ma), and the other during the Upper Jurassic (155-140 Ma) played the central role in the development of the Central Graben rift system, the latter one being the main episode of extension. The geological history is commonly divided into pre-, syn- and post-rifting phases, according to the chronological position of each event to the Upper Jurassic main rifting (Figure 1).

\section{Figure 1}


Throughout its geologic history, the North Sea area was dominated by extension tectonics, thermal doming, rifting and subsidence. The post-Hercynian break-up of Pangaea in the Late Permian initiated the development of the rift systems in the Arctic-North Atlantic and Tethys (Ziegler, 1988). During the Late Permian, a large salt basin formed across the central and southern North Sea. The halokinetic movements of the Zechstein salts played an important role in the post-Permian structural and geological evolution of the basin (Bishop, 1996). Accelerated crustal extension in the late Aalenian and Bajocian was caused by the thermal doming in the area of the Central Graben. The doming caused a truncation of the Permian and Mesozoic sediments, which were partially eroded (Ziegler and van Hoorn, 1988). Uplift movements of the Central North Sea Dome resulted in an enforced opening of the Central Graben, coupled with several important sequences of volcanic activity, especially at the location of the triple-junction of the three grabens (Ziegler, 1988).

During the late Middle and Late Jurassic, the Viking and Central Graben developed into the dominant rift system (Ziegler, 1988). Because of continued crustal expansion and the subsidence of the former site of the North Sea Central Dome, deep marine sediments appeared for the first time in the Central Graben (Underhill, 1998). The Upper Jurassic was a period of eustatic sea level rise. The Upper Jurassic marine transgression progressed throughout the Kimmeridgian (Erratt, et al., 1999). A widespread sedimentation of highly organic-rich shales of Kimmeridgian and Tithonian age occurred in the central North Sea area. These shales form the major source rocks for most of the hydrocarbon accumulations of the Central Graben, the Kimmeridge Shale. Additional source rock potential occurs in the Bathonian to Middle Oxfordian Heather Formation, which has a higher terrigenous input than the shales of the Kimmeridge Clay. The Middle Jurassic (Aalenian to Bajocian) fluvial deposits of the Pentland/Bryne Formation (Fladden Group), contain type III organic matter (Donovan, 1993, Underhill, 1998), but have only minor source rock potential in the Central Graben area. Between the middle Oxfordian to early Kimmeridgian, a main rifting period influenced strongly the graben system (Rattey and Hayward, 1993), which deepened the basins in all three arms.

After the main active rifting phase of the Central Graben, thermal subsidence started and continued more or less uninterrupted until present times.

Repeated sea level changes during the Neogene strongly influenced the sedimentation patterns in the Central Graben. Since the Miocene, sedimentation rates were higher than subsidence rate, accumulating a thickness of the Cenozoic sediments in the middle of the basin along the graben axis of about $3.5 \mathrm{~km}$. After the early Neogene fragmentation of the 
Eurasian-North American crustal plate, the Mesozoic rift system of the North Sea Basin became inactive (Ziegler, 1988).

The study area is located in quadrant 30 (Great Britain), $300 \mathrm{~km}$ east-southeast of Aberdeen (Figure 2), and includes in its deeper sections a high-pressure high-temperature zone (HPHT). This zone is part of a larger province with HPHT conditions, concentrated in the deeper Mesozoic sections of the Central Graben and in the southern part of the Viking Graben. The highly overpressured Mesozoic (pre-rift) clastic reservoirs at 4-5 km burial depths are of Triassic and Middle Jurassic age (Triassic Heron Group and Middle Jurassic Brent Group), and reach temperatures up to $194^{\circ} \mathrm{C}$. The reservoirs are highly overpressured. Petroleum accumulations contain wet gas condensates and black oils. The Upper Jurassic syn-rift shales of the Humber Group, the major source rocks in the Central Graben area (Kimmeridge Clay; Heather formation, Pentland coals), overlie the pre-rift strata. The Upper Cretaceous Chalk Group, consisting primarily of chalks and marls, overlays the pre- and syn-rift strata, and is regionally an effective pressure seal in the Central Graben area (Darby, et al., 1996, Mallon and Swarbrick, 2002, Swarbrick, et al., 2000).

\section{Figure 2}

The geology of Jade and Judy fields have been discussed extensively in the literature (Jones et al., 2005; Swarbrick et al., 2000). Briefly, the Jade structure consists of three NW-SE dipping, tilted fault blocks. The main reservoir is the Joanne sandstone, belonging to the upper part of the Triassic Skagerrak Formation. Reservoir pore pressures exceed 800 bars and temperatures are above $166^{\circ} \mathrm{C}$ at the reservoir apex, and reach values of up to $200^{\circ} \mathrm{C}$ in the deeper sections, as measured in production tests. The Judy field is located on a horst block approximately 20 km south of Jade. Multiple Triassic Skagerrak Formation reservoir units occur, consisting mainly of medium grained quartz-rich sandstones interrupted by shaly sequences. Locally also Jurassic Fulmar sandstone reservoirs are developed. The field is segmented by faults into individual compartments which contain highly variable fluid types, ranging from black oils to gas condensates. Pore pressures in the pre-Cretaceous reservoirs exceed 600 bar and temperatures are around $150^{\circ} \mathrm{C}$.

\section{Model definition}

Numerical modeling for this project was performed using the basin modeling program PetroMod ${ }^{\mathrm{TM}}$ V.8 from IES GmbH, Germany (IES, 2002). The software is based on a forward modeling approach to calculate the geologic evolution of a basin, starting at the oldest and 
finishing at the youngest event, using the present as key to the past (Yalcin, et al., 1997). Its 3D modeling suite includes a full 3D pressure and temperature simulator, which incorporates lateral heat- and pressure transfer through time, as well as fully PVT controlled migration modeling methods.

The 3D basin model was constructed using maps derived from seismic interpretation of 2D and 3D data and converted to depth by ConocoPhillips. A total of 14 surfaces extending from the Balder Formation (Eocene, Figure 1) to the top Permian were available for this study. The maps covered the northern area of quadrant 30 (mainly blocks 30/2 and 30/7) and included both the individual fields as well as their major kitchen areas. As evident from Figure 1, a stratigraphic subdivision of the Tertiary and Quaternary was not available. In order to fill the gap of missing data the top Balder horizon was copied, scaled and used to define the top Oligocene, top Tertiary and sea floor at depths controlled by well tops.

Lithologic properties were assigned to the stratigraphic intervals based on available well data. Each interval was assigned a single, homogeneous lithology as shown in Figure 1. For the initial calibration runs standard PetroMod lithologies available in the software's library were used.

\section{Thermal calibration}

A variety of different heat flow histories for the Central Graben area has been published which can be generally subdivided into two main types, those using a constant heat flow through time (e.g. Schneider and Wolf, 2000) and those using a thermal upwelling model (e.g. Cornford, 1998).

Heat flow calibration was performed assuming initially a constant heat flow history through time, using the compilation of Burley (1993) as starting point for the assessment of the present day heat flow encountered in the study area. Calibration runs using various constant heat flow scenarios resulted in a best fit heat flow of $62 \mathrm{~mW} / \mathrm{m}^{2}$, which matched both formation temperatures and vitrinite reflectance accurately. Once the constant heat flow through time was calibrated the effect of palaeo-heat flow assuming a McKenzie-type rifting heat flow peak and exponential decay (McKenzie, 1978) was tested, assuming an average stretching of $ß=1.5$.

Incorporation of heat flow peaks during Permo-Triassic and Upper Jurassic times (62 and 88 $\mathrm{mW} / \mathrm{m}^{2}$ respectively, Figure 3 ) as well as corresponding times of thermal decay resulted in an excellent match of both well temperatures and vitrinite reflectance data. However, due to the 
great thickness of the Cenozoic strata, heat flow events have only negligible effects on the observed present day VR trends.

The thermal history was calibrated using in addition to the calibration data from the British wells an extensive calibration data set of a 3D model located nearby in the Norwegian sector, where vitrinite reflectance data for over 30 wells was available, as we did not expect the heat flow history of the British and Norwegian sides of the Central Graben to be distinctly different. A precise match of calculated and measured vitrinite reflectance was achieved (Figure 4). Thermal modeling does not show the necessity to use crustal stretching model of Mckenzie, as constant heat flow leads to identical results. That means that the amplitude and the timing of rifting are of minor importance, as long as the source rock is presently at its maximum burial depth. This outcome confirms the results published in the study of Hermanrud (1993).

However, an assumed constant heat flow throughout the entire geological history of a sedimentary basin implies that a basin can subside without any changes in its energy supply (Carr, 2003) and with no rifting-related thermal effects. Even though the results obtained using a constant heat flow produced a good correlation of measured to calculated temperatures, this match is only valid for the present thermal regime and does not allow projection to past settings. Rifting was therefore included, according to the crustal stretching model of McKenzie (1978). Increased heat flow caused by mantle upwelling can lead to thermal doming as postulated for the Middle Jurassic in the study area. The ensuing Upper Jurassic rifting event triggered the development of the prominent central North Sea Graben system. The heat flow history used compares favourably to heat flow histories using a thermal upwelling model.

\section{Figure 3}

\section{Figure 4}

\section{Compositional kinetic models}

In order to compare the reconstructions of pressure evolution histories taking into account the effects of differential compaction and gas generation, compositional kinetic models of hydrocarbon generation had to be defined. For closed conditions gas generation is assumed to be a volume and pressure increasing reaction, as opposed to oil generation which does not result in a net volume increase (Ungerer, et al., 1981). For the calculation of the pressure contribution of the generated gas to the total pore fluids in the system a compositional kinetic 
model capable of describing gas generation rates as well as the compositional evolution of the gas phase during migration and phase separation was required. The PhaseKinetics concept of di Primio and Horsfield (2006) offers the possibility of obtaining a compositional characterisation of generated fluids which is integrated with a bulk kinetic model and correctly predicts hydrocarbon physical properties and phase behaviour as a function of increasing maturity. PhaseKinetics combines open and closed system pyrolysis as well as an empirical correction of generated gas compositions for the definition of the compositional kinetic models. The compositional resolution covers seven individual compounds in the gas range (methane through pentane including iso-butane and iso-pentane, and pseudo compounds representing boiling ranges of C6, C7-14, C15-24, C25-C34, C35-C44, C45-C54 and C55C80 for the liquid range).

For the study area presented here PhaseKinetics for the three source rock intervals Kimmeridge Clay, Heather formation, and Pentland coals were required. A PhaseKinetic model of the Kimmeridge Clay was available from di Primio and Horsfield (2006), the Pentland coals were assumed to be correctly represented by a marine-deltaic kerogen type from di Primio and Horsfield (2006), whereas the Heather formation PhaseKinetics were generated from the bulk kinetics, open and closed system pyrolysis results from Erdmann (1999), who used samples from the Heather Formation, following the PhaseKinetics approach.

One limitation of PhaseKinetics is the fact that the models are valid only for primary cracking. A compositional description of secondary cracking is as yet not available, it was, however, necessary in order to be able to reproduce the gas-condensate compositions encountered in the study area. An iterative approach in the definition of secondary cracking was chosen here, where the modelled reactions were adjusted to reproduce observed compositional trends as discussed below.

The secondary cracking of oil to gas has been documented to differ depending on whether cracking occurs in the source or in the reservoir (Dieckmann, et al., 1998, Schenk, et al., 1997). While the published oil to gas cracking models describe the bulk conversion of the liquid fraction into gas, the compositional resolution of the PhaseKinetics data allows for the characterisation of secondary cracking for six individual carbon chain length ranges. As PetroMod V 8.0 only allows the input of a single secondary cracking reaction, it is impossible to differentiate between in-source and in-reservoir processes. In order to take into account the possibility of both processes playing a role in the cracking of oil to gas in sedimentary basins, the stability of the liquid fractions was varied systematically within the range defined by the 
in-reservoir and in-source oil to gas cracking kinetics of (Schenk, et al., 1997) and Dieckmann et al. (1998) (Figure 5).

\section{Figure 5}

In the iterative development of the secondary cracking definition for reasons of simplicity the frequency factor was maintained constant and only activation energies (A) varied.

The activation energy $\left(E_{A}\right)$ defines the minimum energy required to initiate a specific chemical reaction, while the frequency factor (or pre-exponential factor) is the preexponential constant in the Arrhenius equation. The frequency factor chosen represents an average of values quoted in the literature for secondary cracking: Vandenbroucke et al. (1999) determined a frequency factor of $1.37 * 10^{14} 1 / \mathrm{s}\left(\sim 1 * 10^{28}\right.$ 1/Ma) for bulk oil cracking and $6.1 * 10^{17} 1 / \mathrm{s}\left(\sim 2 * 10^{31} 1 / \mathrm{Ma}\right)$ for individual fractions of the liquid fraction; Horsfield et al. (1992) found a value of $1.1 * 10^{16} 1 / \mathrm{s}\left(\sim 3.5 * 10^{29} 1 / \mathrm{Ma}\right)$ and (Kuo and Michael, 1994) used $2.85 * 10^{16} 1 / \mathrm{s}\left(\sim 1 * 10^{30} 1 / \mathrm{Ma}\right)$ for bulk oil cracking. Based on these data an average frequency factor of $1 * 10^{30} 1$ /Ma was chosen.

A single activation energy for the cracking reaction was assigned to each of the liquid pseudo compounds. Activation energies were varied between $55 \mathrm{kcal} / \mathrm{mol}$ (lowest Ea from Dieckmann et al., 1998) and $70 \mathrm{kcal} / \mathrm{mol}$ (highest significant Ea from Schenk et al. 1997). For comparison, activation energies for secondary cracking ranged between 54.5 and 68.2 in Vandenbroucke et al. (1999). Using the activation energy distribution shown in Table 1, the GOR - saturation pressure trend of natural fluids from the study area (Figure 6), was reproduced satisfactorily.

\section{Figure 6}

\section{Table 1}

\section{Pressure modelling}

While most published work relates overpressure generation to either disequilibrium compaction or gas generation, the methods used to reach these conclusions are generally unsatisfactory. For example, Swarbrick and Osborne (1998) used 2D basin modeling in combination with fluid inclusion studies to conclude that overpressure generation in the same study area as investigated here was dominantly controlled by disequilibrium compaction. Isaksen (2004) concluded in his investigation of the evolution of the Central Graben, that 
overpressure was mainly related to gas generation. His conclusions were, however, drawn from a correlation of overpressure with elevated in-situ temperatures. These two examples demonstrate the lack of a systematic test of the effects of different mechanisms on the total overpressure generated. In this study, we tested two scenarios for the generation of severe overpressure:

- Scenario 1: Disequilibrium compaction as main pressure mechanism

- Scenario 2: The combination of disequilibrium compaction and overpressure resulting from gas generation

In PetroModTM, default lithologies can be modified. Besides the default lithologies available in PetroMod ${ }^{\mathrm{TM}}$, the software allows the definition of user-defined lithologies, either via input in a spreadsheet, or via mixing of two or more default lithologies. In order to reproduce the present-day pressure distribution in scenario 1, the properties of the cap rock lithologies, more specifically the porosity-permeability relationships, are varied until a satisfactory match is obtained. This method has been described by Swarbrick and Osborne (1998) and is commonly used in pressure studies using 2D or 3D basin modelling. For our study area two pressure seals have been documented:

- A minor, locally effective pressure seal has been reported in the Eocene Shales (Darby, et al., 1996),

- $\quad$ and an effective pressure seal in the lower part of the Chalk Group, the Hod formation (Darby, et al., 1996, Mallon and Swarbrick, 2002, Swarbrick, et al., 2000), as shown in the pressure gradients in Figure 7.

\section{Figure 7}

In total an overpressure of about $45 \mathrm{MPa}$ occurs in the reservoir units. In the editor-interface of the modelling software PetroMod ${ }^{\mathrm{TM}}$, the permeabilities of both sealing units at minimum porosity (defined as $5 \%$ ) were iteratively reduced to values of $10^{-8.5} \mathrm{mD}$ for the Hod formation and $10^{-6.5} \mathrm{mD}$ respectively for the Eocene shales in order to achieve a good match with the observed pore pressures (Figure 8). The porosity-permeability trends defined were based on the relationship put forward by Swarbrick et al. (2000).

The evolution of pore pressure as a function of burial resulting from the definition of the pressure seals described above is shown in Figure 8. Pore pressure in the reservoir increased above hydrostatic levels very early on in the burial history. Overpressure in the magnitude of $10 \mathrm{MPa}$ already occurred as early as $70 \mathrm{Ma}$ ago, and increased to the present day overpressure of $40 \mathrm{MPa}$, developing more or less continuously, except for an accelerated increase during the last million years. 
The volumetric contribution of generated gas to the available pore fluids is calculated in PetroMod as a function of pressure and temperature as well as the compressibility of the gas phase. For an ideal gas under isothermal conditions the relationship is

$$
C \equiv-\frac{1}{V}\left(\frac{\partial V}{\partial P}\right)_{T}=\frac{1}{P}
$$

Where $\mathrm{C}$ is the compressibility $\left[\mathrm{Pa}^{-1}\right], \mathrm{V}$ is volume $\left[\mathrm{m}^{3}\right]$ and $\mathrm{P}$ pressure $[\mathrm{Pa}]$. In order to take non-ideal gas behaviour into account, for example in the case of natural gas, the compressibility factor $\mathrm{z}$ must be introduced.

$$
V=\frac{z R T}{P}
$$

Where $\mathrm{R}$ is the ideal gas constant $\left[\mathrm{J} \mathrm{mol}^{-1} \mathrm{~K}^{-1}\right]$ and $\mathrm{T}$ temperature $[\mathrm{K}]$. Including the compressibility factor $\mathrm{z}$ into the compressibility equation leads to:

$$
C \equiv-\frac{1}{V}\left(\frac{\partial V}{\partial P}\right)_{T}=-\left(\frac{\frac{\partial(z(P))}{\partial P}}{z(P)}-\frac{1}{P}\right)=\frac{1}{P}-\frac{1}{z(P)}\left(\frac{\partial z(P)}{\partial P}\right)_{T}
$$

For a given pressure and temperature this equation can be simplified using the bulk modulus (reciprocal of compressibility) to:

$$
\begin{gathered}
C=\frac{1}{P}-\frac{1}{Z}\left(\frac{\partial z}{\partial P}\right)_{T}=\frac{Z-P \cdot\left(\frac{\partial z}{\partial P}\right)_{T}}{P \cdot Z} \\
\frac{1}{C}=\frac{P \cdot Z}{Z-P \cdot\left(\frac{\partial Z}{\partial P}\right)_{T}}
\end{gathered}
$$

The gas compressibility factor $\mathrm{z}$ was determined based on the reported reservoir fluid composition of Jade field, using the PVT simulator software PVTSim V. 13 (Calsep, A/S, Denmark). The z-factor of the Jade condensates was calculated to lie close to 1.2. Gas compressibility was taken into account in Petromod by inputting the bulk modulus (1/C) of the natural gas phase at reservoir pressure and temperature as calculated above.

In the implementation of the gas compressibility factor for the calculation of the volumetric contribution of the gas phase, the use of a single gas compressibility factor $z$ implies the tacit assumption that gas composition and, hence, deviation from ideal gas behaviour remains constant throughout basin evolution. This is obviously not the case in a natural system. 
However, results from the disequilibrium compaction case showed that the largest increase in overpressure seems to be associated to the latest burial event. Hence, the volumetric impact of generated gas will also be largest at this time, such that the use of the present day fluids compressibility factor is considered appropriate.

In the implementation of the gas compressibility factor for the calculation of the volumetric contribution of the gas phase, the use of a single gas compressibility factor $z$ implies the tacit assumption that gas composition and, hence, deviation from ideal gas behaviour remains constant throughout basin evolution. This is obviously not the case in a natural system. However, results from the disequilibrium compaction case showed that the largest increase in overpressure seems to be associated to the latest burial event. Hence, the volumetric impact of generated gas will also be largest at this time, such that the use of the present day fluids compressibility factor is appropriate.

In order to reproduce the observed reservoir pressures in the 3D model cap rock permeabilities had to be increased significantly as compared to the disequilibrium compaction case. In order to calibrate the model (Figure 8, left panel) permeabilities at minimum porosity had to be increased to values of $10^{-5} \mathrm{mD}$ for all cap rocks, i.e. up to three orders of magnitude higher permeabilities than for the case where gas generation was not taken into account. The evolution of pore pressure in the reservoir based on scenario 2 (Figure 8, right panel) indicates a much later onset of overpressuring, whereby hard overpressure only occurs as a result of the latest burial event.

\section{Figure 8}

Verification of predicted pressure histories is a difficult task, as palaeo-pressure data is only rarely available. One technique applicable for palaeo pressure determination is confocal laser scanning microscopy, which, in combination with PVT simulation software and fluid compositional information from the reservoir where the samples were taken, allows the determination of GOR and trapping pressure and temperature conditions of hydrocarbon bearing fluid inclusions. Aplin et al. (1999) developed this technique and applied it to samples from Judy field in a later publication (Aplin, et al., 2000).

\section{Figure 9}

The pT conditions of fluid inclusion entrapment determined by Aplin et al. (2000) are shown in Figure 9 together with the reservoir formation pT trends as a function of burial. The pore pressure-curve of the seal lithologies in Figure 9 clearly shows that the simulation of scenario 1 overestimates the pressure evolution, whereas the simulation of combined disequilibrium 
compaction and gas generation, as introduced in the scenario 2, results in an excellent match of pT evolution and palaeo pT data from fluid inclusions.

\section{Phase prediction}

The compositional kinetic hydrocarbon generation models described above were used to simulate the generation, migration and phase behaviour of petroleum. The kinetic models were defined in both pressure evolution scenarios discussed previously.

The kitchen areas of the two main accumulations under study, Jade and Judy fields, differ both in extent and maturity. Jade field is charged mainly from the north, where a very deep kitchen is immediately adjacent to the flanks of the horst structure which hosts the field. Judy field lies further to the east and has access to at least two different source rock kitchens, one to the south and the other to the north (part of the same basin which feeds Jade). The drainage areas for these two accumulations are shown in Figure 10. Judy field is additionally compartmentalised, whereby different portions of the field have access to the different kitchen areas. The strong fluid compositional variability of the field which was described by Swarbrick et al. (2000) is, hence, most likely a direct result of this situation.

\section{Figure 10}

According to the modelling results shown in Figure 12, hydrocarbon generation (as defined by a TR of $10 \%$ ) starts at $115 \mathrm{Ma}$ in the depocenter of the northern kitchen, kerogen transformation progresses rapidly in the deepest parts of the kitchen and total transformation is reached by $80 \mathrm{Ma}$. The flanks of the northern kitchen area mature later and the source rock sections closest, and in part overlying the Jade structure are late mature today (Figure 11). The southern kitchen of Judy field enters the oil window at roughly $75 \mathrm{Ma}$ and matures up to the late oil window at present. Kerogen transformation ratios for exemplary positions within the two main kitchen areas are shown in Figure 12.

\section{Figure 11}

\section{Figure 12}

Predicted present-day hydrocarbon compositions in the Jade and Judy structures closely match the values observed in the field, both with respect to molar compositions as well as GOR and saturation pressure.

Table 2 lists the compositions and the physical properties of the reservoir fluids as monitored and modelled. Interestingly, both pressure evolution scenarios result in very similar 
compositional predictions, indicating that the pressure regime did not significantly control the fluid evolution.

\section{Table 2}

Having established a good match of present day fluid compositions, the evolution of the reservoir fluids during filling can be investigated. Figure 13 shows the evolution of GOR of the individual phases in the Jade reservoir as a function of time for both pressure evolution scenarios. In the case of the simulation which took disequilibrium-compaction and gas generation into account (Scenario 2), first hydrocarbon emplacement occurs at around 100 $\mathrm{Ma}$, the fluid in place consists of an oil leg and a gas cap. GOR differences between the two phases are extreme, due to the very shallow position of the reservoir. Reservoir burial and hydrocarbon filling continue throughout the entire Cretaceous in Figure 13. During this time a two-phase system still continues to exist in the reservoir, whereby the liquid GOR increases and the gas GOR decreases due to a combination of increasing maturity of the fluids arriving in the reservoir as well as increasing pT conditions of the reservoir. The separation of the saturation pressure (Psat) line from the reservoir pore pressure indicates undersaturation of the reservoir fluid. At 50 Ma fluid overpressure reaches a first maximum and results in the undersaturation of the hydrocarbon phase (Figure 14). At this time the reservoir fluid consists of light oil (GOR of roughly $500 \mathrm{Sm}^{3} / \mathrm{Sm}^{3}$ ). As the source rocks mature and move into the gas window, arriving fluids are characterised by increasing proportions of gas. Mixing with the fluid already emplaced in the reservoir results in a gradual increase of the total GOR and a shift of the fluid type to an undersaturated gas condensate as encountered today. Throughout this last burial phase the reservoir fluids remain undersaturated.

\section{Figure 13}

In the simulation taking disequilibrium-compaction as the only pressure generation mechanism (Scenario 1, Sc 1) the first hydrocarbon accumulation also occurs at $100 \mathrm{Ma}$. Oil and gas phase GORs evolve as described above with the exception that undersaturation occurs at $15 \mathrm{Ma}$. Following undersaturation, fluid evolution goes through the same trend as for the former study in that GOR increases systematically until the present day situation.

\section{Figure 14}

The filling history of the Judy structure shows very similar features as described for Jade. Based on the combined pressure model (Scenario 2), a first hydrocarbon emplacement occurred at around $80 \mathrm{Ma}$. The initially low GOR is confirmed by the study of Swarbrick et 
al. (2000), who performed palaeo-pressure estimations on four wells in the Judy field using fluid inclusions in quartz cements and 2D basin modeling. Until the last rapid burial event in the Quaternary, the reservoir contained a two-phase system (oil and gas), which evolved to an undersaturated black oil as encountered in some of Judy’s compartments nowadays.

According to the results based solely on disequilibrium compaction (Scenario 1), the first hydrocarbon accumulation occurred at 80 (Figure 15). Oil and gas phase GORs evolve as described above with the exception that undersaturation occurs already at $60 \mathrm{Ma}$, as indicated by the separation of the saturation pressure (Psat) line from the reservoir pore pressure (Ppore) line. Following undersaturation, fluid evolution goes through the same trend as for the Jade field in that GOR increases systematically until the present day GOR of $961 \mathrm{Sm}^{3} / \mathrm{Sm}^{3}$ is reached.

GOR values determined on fluid inclusions from the reservoir formation in Judy field ranged between 50-400 Sm $3 / \mathrm{Sm}^{3}$, as reported by Aplin et al. (2000). As discussed earlier trapping temperatures and pressures from these fluid inclusion analyses indicated that inclusion formation occurred between 2 and 10 Ma (Figure 9). The GOR prediction from basin modelling for this time span in Judy field is $276 \mathrm{Sm}^{3} / \mathrm{Sm}^{3}$, a value well within the range reported for the petroleum fluid inclusions from the reservoir. The use of fluid inclusion data as calibration for palaeo fluid properties provides, thus, further support for the correctness of the fluid evolution reconstruction.

\section{Figure 15}

\section{Discussion}

The integrated modelling approach chosen here combining different mechanisms of pressure generation with phase predictive compositional kinetic models clearly indicates the complexity of correctly reproducing basin evolution. While a simplistic approach, such as only the consideration of disequilibrium compaction as a pressure generating mechanism, leads to a satisfactory match of observed and modelled present-day overpressure, the comparison with alternative scenarios and especially the calibration to available palaeopressure and compositional data reveal that an integrated approach is required to come closer to correctly reproducing the natural system.

The difference of three orders of magnitude in required minimum seal permeability between the two pressure generation scenarios modelled here indicates that gas generation contributes 
significantly to overpressure. Including gas generation drastically changes overpressure evolution as a function of time (Figure 8) and results in a much stronger link between overpressure magnitude and burial history. In the HPHT zone of the Central Graben studied here, the present-day level of hard overpressure is reached only during the last burial event, where sediment layers of over $700 \mathrm{~m}$ thicknesses were deposited in the last million years or less (Figure 8). Such a strong link between overpressure development and rapid burial has equally been postulated for the Haltenbanken area, also based on evidence from fluid inclusions (Karlsen, et al., 2004).

The magnitude of overpressure contribution from the generation of gas depends on the intensity of gas generation in the system (which is kinetically controlled) as well as the compressibility of the gas phase. As discussed earlier the latter depends strongly on gas composition. A first approximation of the effect of the volumetric contribution of gas on overpressure generation as a function of its compressibility can be derived from the comparison of the molar volume evolution of an ideal gas as a function of pressure and temperature as compared to that of a natural subsurface gas phase using the respective compressibility factors. The difference in compressibility factors (z) amounts to up to $20 \%$ (at the pressure and temperature conditions of the Jade reservoir), and, hence, the volumteric contribution of natural gas generation to the magnitude of overpressure can also vary by at least this amount depending on composition. It must be taken into account here, that $z$ factors reach highest values where pressure and temperature are significantly higher than the fluids critical pressure and temperature; in the case of the Jade fluid reservoir pressure was roughly $50 \mathrm{MPa}$ higher than the critical pressure and reservoir temperature was close to $180^{\circ} \mathrm{C}$ higher than the fluids critical temperature. Obviously these conditions are only so extreme in HPHT settings and hence the effect of $z$ is maximal in such areas.

This implies that for a correct inclusion of this effect in the calculation of overpressure generation the evolution of gas composition should be taken into account during the simulation, especially in HPHT settings. Theoretically this would be possible already now, as the compositional kinetics models used in this study predict correct gas compositions. The implementation is, however, still not available in current day basin modelling packages. It should also be taken into account that inclusion of additional pressure generating processes, such as kinetically controlled chemical compaction, would increase the discrepancy between the overpressure evolution scenarios discussed here.

With respect to basin modelling workflows our results indicate that, contrary to established procedures, where thermal modelling and calibration is performed prior to pressure 
calibration, and compositional modelling of hydrocarbon generation and migration is done as a final step (if at all), in severely overpressured settings hydrocarbon generation and migration has to be taken into account already for model calibration, i.e. at a very early stage of the basin modelling workflow. This has, of course, implications for computation times and model resolution, as simulation runs including hydrocarbon generation and migration take commonly (much) longer than simple thermal modelling runs.

The compositional evolution of the petroleum phases generated were modelled using a 14 compound kinetic model (di Primio and Horsfield, 2006) combined with a description of secondary cracking which was empirically defined by comparison of predicted compositions and observed natural fluid compositions. The kinetic models predicted fluid compositional evolution in a highly satisfactory manner and reproduced the observed distributions of black oil to gas condensates both at present day as well as in the last few time-steps where calibration data were available.

The influence of the overpressure generation history had remarkably little effect on the compositional evolution of the reservoir fluid, especially with respect to the reproduction of present day compositions. Interestingly, the evolution of reservoir fluid saturation pressures (Figure 14) showed the strongest difference between the two pressure scenarios modelled here. The fact that the reservoir fluids of Jade field in Scenario 2 (the simulation which took gas generation as a pressure generating mechanism into account) became undersaturated significantly earlier than those of Scenario 1 can be explained by a stronger leakage of gas (during the two-phase stages of reservoir fluid evolution) through the higher permeability cap rocks of Scenario 1.

In summary, the integration of gas generation as a pressure generating mechanism and compositional modelling of petroleum generation and migration in 3D basin modelling provided a significant step forward in understanding the process involved and their effects. This approach led as well to a better characterisation of fluid compositional evolution during burial and allowed the reconstruction of the reservoir filling history of the HPHT reservoirs studied.

\section{Conclusions}

3D basin modelling of a study area in Quadrant 30, UK North Sea containing the fields Jade and Judy allowed the characterisation of the burial, thermal, pressure and hydrocarbon generation and migration histories, plus the description of the reservoir fluid evolution during reservoir filling. 
Comparison of predictions of overpressure evolution based on 3D basin modelling, assuming differential compaction alone, as well as the combination of differential compaction and gas generation as pressure generating processes, indicates that gas generation plays a significant role in subsurface overpressure evolution. Comparison of the calculated pressure evolution histories with fluid inclusion pressure-temperature data indicates that gas generation must be taken into account when modelling overpressure.

Severe overpressures as observed today in the reservoirs are linked to a significant pressure increase during the latest burial event.

The integration of bulk kinetics, compositional information from closed system pyrolysis following the PhaseKinetics approach, and regional PVT data allowed the definition of compositional kinetic models which correctly reproduced observed fluid compositions and physical properties (GOR and saturation pressure) using 3D basin modelling.

Our results indicate that in the Jade and Judy reservoirs early emplacement of petroleum occurred. This first hydrocarbon charge consisted of a two phase system (oil and gas) whereby the vapour phase dominated volumetrically.

The evolution of the fluid phases in the reservoirs in the further burial of the Central Graben evolved along similar lines: reservoir fluids remained in two phases while the GOR increased systematically due to source rock maturation and the production of gas-richer petroleum compositions. Overpressuring of the reservoir fluids led to their undersaturation, such that today undersaturated gas-condensates are encountered locally in both fields. The present fluid composition is most likely a function of both primary and secondary cracking processes. 


\section{Acknowledgements}

Volkmar Neumann thanks his supervisor Brian Horsfield for supervision and support, as well as the German Science Foundation (DFG, DI 880/1) for funding. Data and support provided by ConocoPhillips and NorskHydro is gratefully appreciated. The authors would like to thank B. Krooss and R. Sachsenhofer for providing excellent reviews which helped significantly improve this manuscript. 


\section{References}

Aplin, AC, Larter, SR, Bigge, MA, Macleod, G, Swarbrick, RE and Grunberger, D (2000) PVTX history of the North Sea's Judy oilfield. Journal of Geochemical Exploration 69-70: 641-644

Aplin, AC, Macleod, G, Larter, SR, Pedersen, KS, Sorensen, H and Booth, T (1999) Combined use of Confocal Laser Scanning Microscopyand PVT simulation for estimating the composition andphysical properties of petroleum in fluid inclusions. Marine and Petroleum Geology 16 (2): 97-110

Behar, F, Kressmann, S, Rudkiewicz, JL and Vandenbroucke, M (1992) Experimental simulation in a confined system and kinetic modelling of kerogen and oil cracking. Organic Geochemistry 19 (1-3): 173-189

Bishop, DJ (1996) Regional distribution and geometry of salt diapirs and supra-Zechstein Group faults in the western and central North Sea. Marine and Petroleum Geology 13 (4): 355-364

Brown, S (1991) Stratigraphy of the oil and gas reservoirs - U.K. continental shelf. In: United Kingdom oil and gas fields - 25 years commemorative volume. Geological Society, London, 14: 9-18

Burley, SD (1993) Models of burial diagenesis for deep exploration plays in Jurassic fault traps of the Central and Northern North Sea. In: Petroleum Geology of Northwest Europe: Proceeding of the 4th Conference. Geological Society, London, London, 2: 1353-1375

Carr, AD (2003) Thermal history model for the South Central Graben, North Sea, derived using both tectonics and maturation. International Journal of Coal Geology 54 (1-2): 3-19

Cayley, GT (1986) Hydrocarbon migration in the central North Sea. In: Petroleum Geology of Northwest Europe: Proceeding of the 3rd Conference. Geological Society, London, London, 1: 549-556

Cornford, C (1998) Source rocks and hydrocarbons of the North Sea. In: Petroleum geology of the North Sea: Basic concepts and recent advances. Blackwell Science Geology \& Petroleum Geology, Oxford, United Kingdom, pp 376-462

Darby, D, Haszeldine, RS and Couples, GD (1996) Pressure cells and pressure seals in the UK Central Graben. Marine and Petroleum Geology 13 (8): 865-878

di Primio, R and Horsfield, B (2006) From petroleum type organofacies to hydrocarbon phase prediction. AAPG Bulletin 90 (7): 1031-1058

di Primio, R and Skeie, JE (2004) Development of a compositional kinetic model for hydrocarbon generation and phase equilibria modelling: a case study from Snorre Field, Norwegian North Sea. In: Understanding Petroleum Reservoirs: towards an Intefrated Reservoir Engineering and Geochemical Approach. Geological Society Special Publication 237, London: 157-174

Dieckmann, V, Schenk, HJ, Horsfield, B and Welte, DH (1998) Kinetics of petroleum generation and cracking by programmed-temperature closed-system pyrolysis of Toarcian Shales. Fuel 77 (1-2): 23-31

Donovan, AD, Djakic, A. W., Ioannides, N. S., Garfield, G. R., Jones, C. R. (1993) Sequence stratigraphic control on Middle and Upper Jurassic reservoir distribution within the UK Central North Sea. In: Petroleum geology of northwest Europe: Proceeding of the 4th conference. Geological Society, London, 1: 251-269

Erdmann, M (1999) Gas generation from overmature Upper Jurassic source rocks, northern Viking Graben Doctoral, RWTH, Aachen. Berichte des Forschungszentrums Jülich; 3700, pp 1- 128

Erratt, D, Thomas, GM and Wall, GRT (1999) The evolution of the central North Sea Rift. In: Petroleum geology of Northwest Europe; proceedings of the 5th conference London, United Kingdom The Geological Society of London Conference. 5; 63-82

Espitalie, J, Ungerer, P, Irwin, I and Marquis, F (1988) Primary cracking of kerogens; experimenting and modeling $\mathrm{C}_{1}, \mathrm{C}_{2}-\mathrm{C}_{5}, \mathrm{C}_{6}-\mathrm{C}_{15}$ and $\mathrm{C}_{15+}$ classes of hydrocarbons formed. In: Advances in organic geochemistry 1987; Part II, Analytical geochemistry; proceedings of the 13th international meeting on Organic geochemistry Oxford-New York, International Pergamon 13; 4-6: 893-899

Glennie, KW (1998) Petroleum geology of the North Sea; basic concepts and recent advances. Blackwell Science Geology \& Petroleum Geology, Oxford, United Kingdom: 636-658

Hermanrud, C (1993) Basin modelling techniques; an overview. In: Basin modelling; advances and applications; proceedings of the Norwegian Petroleum Society conference New York, International Elsevier 3: 1-34 
Horsfield, B, Schenk, HJ, Mills, N and Welte, DH (1992) An investigation of the in-reservoir conversion of oil to gas; compositional and kinetic findings from closed-system programmed-temperature pyrolysis. In: Advances in organic geochemistry 1991; Part 1, Advances and applications in energy and the natural environment. Pergamon, Oxford-New York, International, 19; 1-3: 191-204

Isaksen, G (2004) Central North Sea hydrocarbon systems: Generation, migration, entrapment, and thermal degradation of oil and gas. AAPG Bulletin 88 (11): 1545-1572

Jones A. D., Auld, H. A., Carpenter, T. J., Fetkovich, E., Palmer, I. A., Rigatos, E. N., and Thompson, M. W. (2004) Jade Field: An innovative approach to high-pressure/high-temperature field development. In Doré A.G. and Vining, B.A. (eds) Petroleum Geology: North-West Europe and Global Perspectives-Proceedings of the $6^{\text {th }}$ Petroleum Geology Conference, Geological Society London, 2: 269-283.

Karlsen, DA, Skeie, JE, Backer, OK, Bjorlykke, K, Olstad, R, Berge, K, Cecchi, M, Vik, E and Schaefer, RG (2004) Petroleum migration, faults and overpressure; Part II, Case history; the Haltenbanden petroleum province, offshore Norway. In: Understanding petroleum reservoirs; towards an integrated reservoir engineering and geochemical approach. Geological Society of London, London, United Kingdom, 237: 305-372

Kuo, LC and Michael, GE (1994) A multicomponent oil-cracking kinetics model for modeling preservation and composition of reservoired oils. Organic Geochemistry 21 (8-9): 911-925

Mallon, AJ and Swarbrick, RE (2002) A compaction trend for non-reservoir North Sea Chalk. Marine and Petroleum Geology 19 (5): 527-539

Mann, DM and Mackenzie, AS (1990) Prediction of pore fluid pressures in sedimentary basins. Marine and Petroleum Geology 7 (1): 55-65

McKenzie, D (1978) Some remarks on the development of sedimentary basins. Earth and Planetary Science Letters 40 (1): 25-32

Osborne, MJ and Swarbrick, RE (1997) Mechanisms of generating overpressure in sedimentary basins: A reevaluation. AAPG Bulletin (American Association of Petroleum Geologists) 81 (6): 1023-1041

Rattey, RP and Hayward, AP (1993) Sequence stratigraphy of a failed rift system: The Middle Jurassic to Early Cretaceous basin evolution of the Central and Northern North Sea. In: Petroleum Geology of Northwest Europe: Proceeding of the 4th Conference. Geological Society, London, London, 1: 215-249

Schenk, HJ, Di Primio, R and Horsfield, B (1997) The conversion of oil into gas in petroleum reservoirs. Part 1: comparative kinetic investigation of gas generation from crude oils of lacustrine, marine and fluviodeltaic origin by programmed-temperature closed-system pyrolysis. Organic Geochemistry 26 (7-8): 467-481

Schenk, HJ and Horsfield, B (1993) Kinetics of petroleum generation by programmed-temperature closedversus open-system pyrolysis. Geochimica et Cosmochimica Acta 57 (3): 623-630

Schneider, F and Wolf, S (2000) Quantitative HC potential evaluation using 3D basin modelling: application to Franklin structure, Central Graben, North Sea, UK. Marine and Petroleum Geology 17 (7): 841-856

Swarbrick, RE, Osborne, MJ, Grunberger, D, Yardley, GS, Macleod, G, Aplin, AC, Larter, SR, Knight, I and Auld, HA (2000) Integrated study of the Judy Field (Block 30/7a) - an overpressured Central North Sea oil/gas field. Marine and Petroleum Geology 17 (9): 993-1010

Swarbrick, RE, Osborne, M. J. (1998) Mechanisms that generate abnormal pressures: An overview. In: Abnormal pressures in hydrocarbon environments: AAPG Memoir 70. The American Association of Petroleum Geologists, Tulsa, Oklahoma, USA, 70: 13-34

Tissot, B and Espitalie, J (1975) L'evolution thermique de la matiere organique des sediments; applications d'une simulation mathematique; Potentiel petrolier des bassins sedimentaires et reconstitution de l'histoire thermique des sediments. Revue de l'Institut Francais du Petrole et Annales des Combustibles Liquides 30 (5): 743-777

Underhill, JR (1998) Jurassic. In: Petroleum geology of the North Sea: Basic concepts and recent advances. Blackwell Science Geology \& Petroleum Geology, Oxford, United Kingdom: 245-293

Ungerer, P, Behar, E and Discamps, D (1981) Tentative calculation of the overall volume expansion of organic matter during hydrocarbon genesis from geochemistry data; implications for primary migration. Advances in organic geochemistry 10: 129-135

Vandenbroucke, M, Behar, F and Rudkiewicz, JL (1999) Kinetic modelling of petroleum formation and cracking: implications from the high pressure/high temperature Elgin Field (UK, North Sea). Organic Geochemistry 30 (9 SU): 1105-1125 
Wendebourg, J (2000) Modeling multi-component petroleum fluid migration in sedimentary basins. Journal of Geochemical Exploration 69-70: 651-656

Yalcin, MN, Littke, R and Sachsenhofer, RF (1997) Thermal history of sedimentary basins. In: Petroleum and basin evolution; insights from petroleum geochemistry, geology and basin modeling. Springer, Berlin, Federal Republic of Germany, pp 71-167

Ziegler, PA (1988) Evolution of the Arctic-North Atlantic and the Western Tethys. In: AAPG Memoir 43. The American Association of Petroleum Geologists (AAPG), Tulsa, Oklahoma, USA, pp 1- 198

Ziegler, PA and van Hoorn, B (1988) Evolution of the North Sea Rift system. Geological Association of Canada, Waterloo, ON, Canada, pp 1-138 


\section{Figure Index}

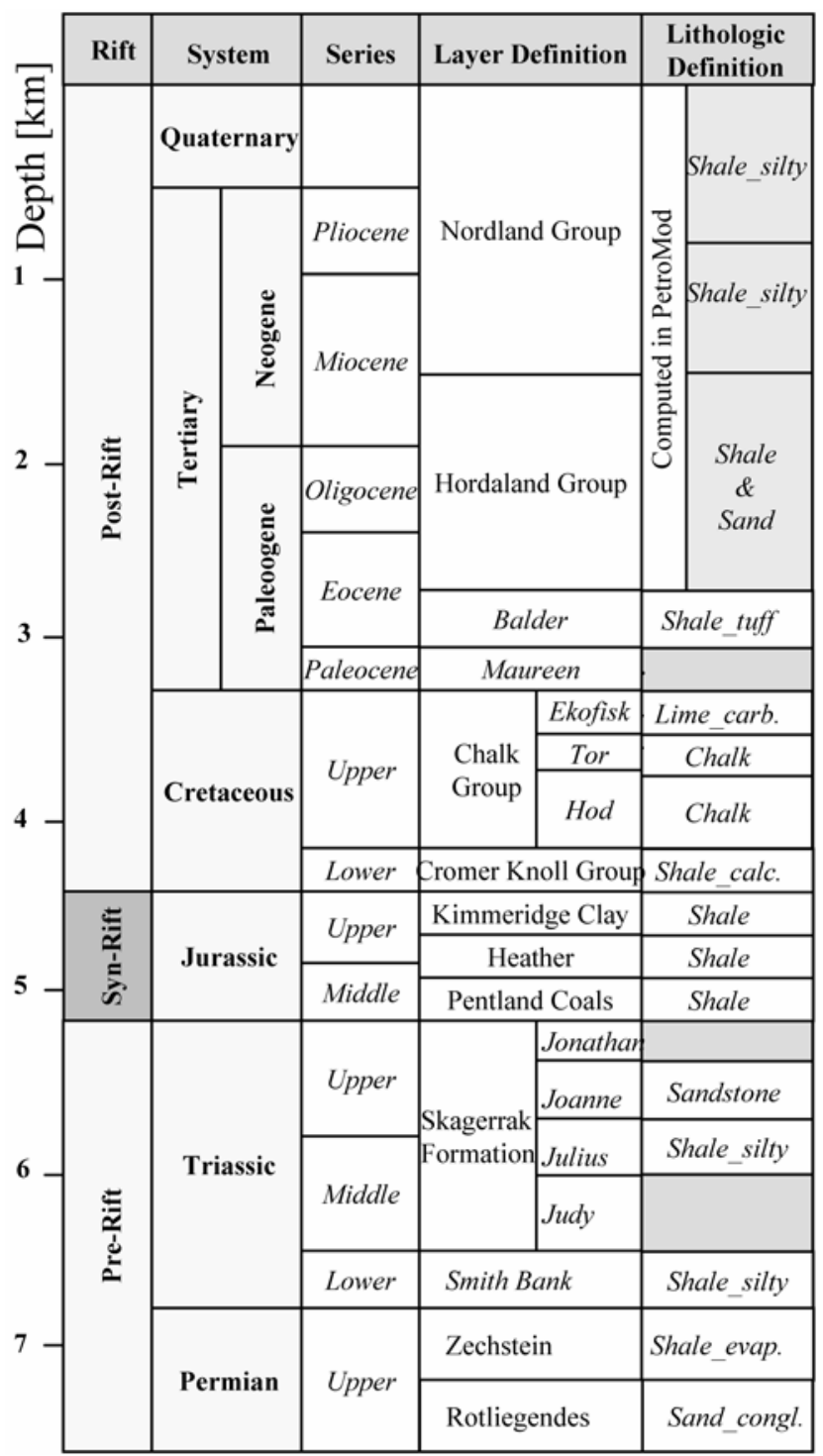

Figure 1

Stratigraphic profile of the Jade well 30/2c-4, including the lithologies assigned in the modeling software. 


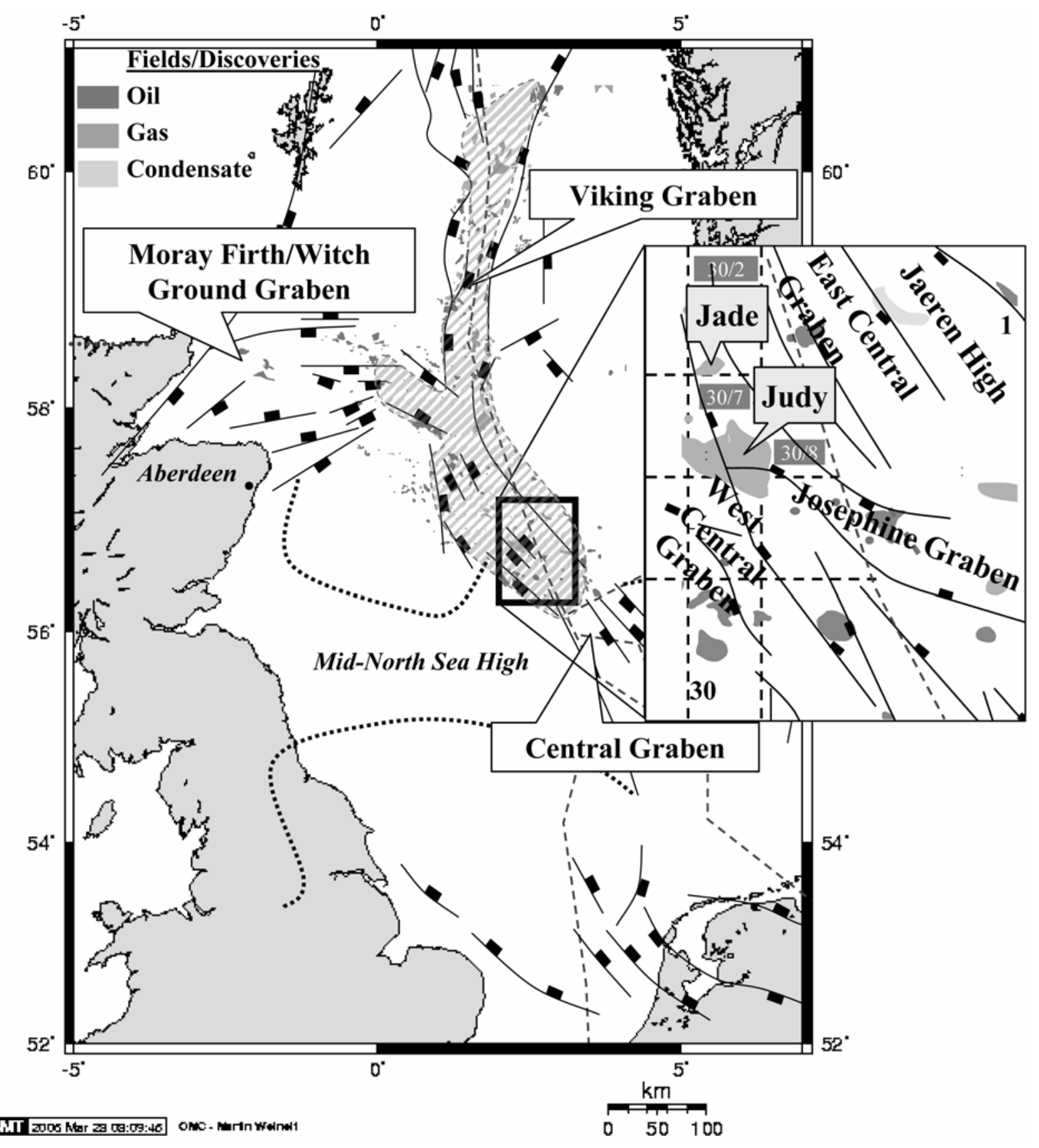

Figure 2

Location map showing the North Sea rift system including, its structural elements (modified, after Brown (1991)), study area (box), fields/discoveries ; HPHT province (shaded area) and national boundaries (lines). 


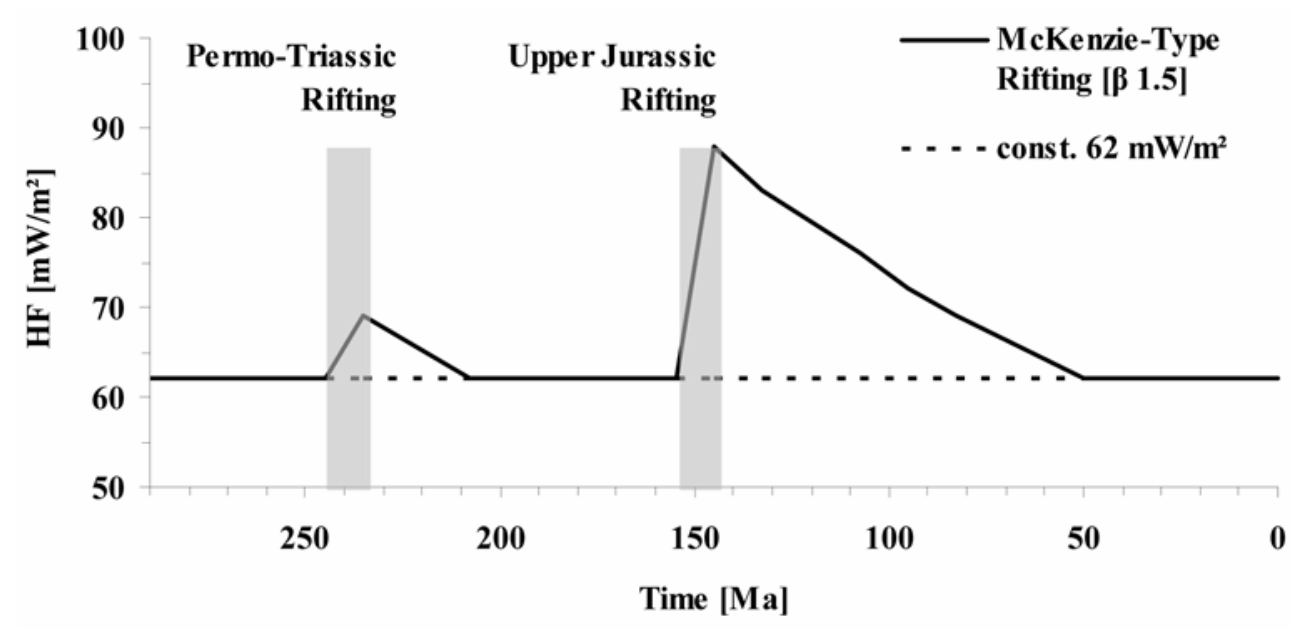

Figure 3

McKenzie-type rifting heat flow scenario assigned as lower thermal boundary for the numerical model.
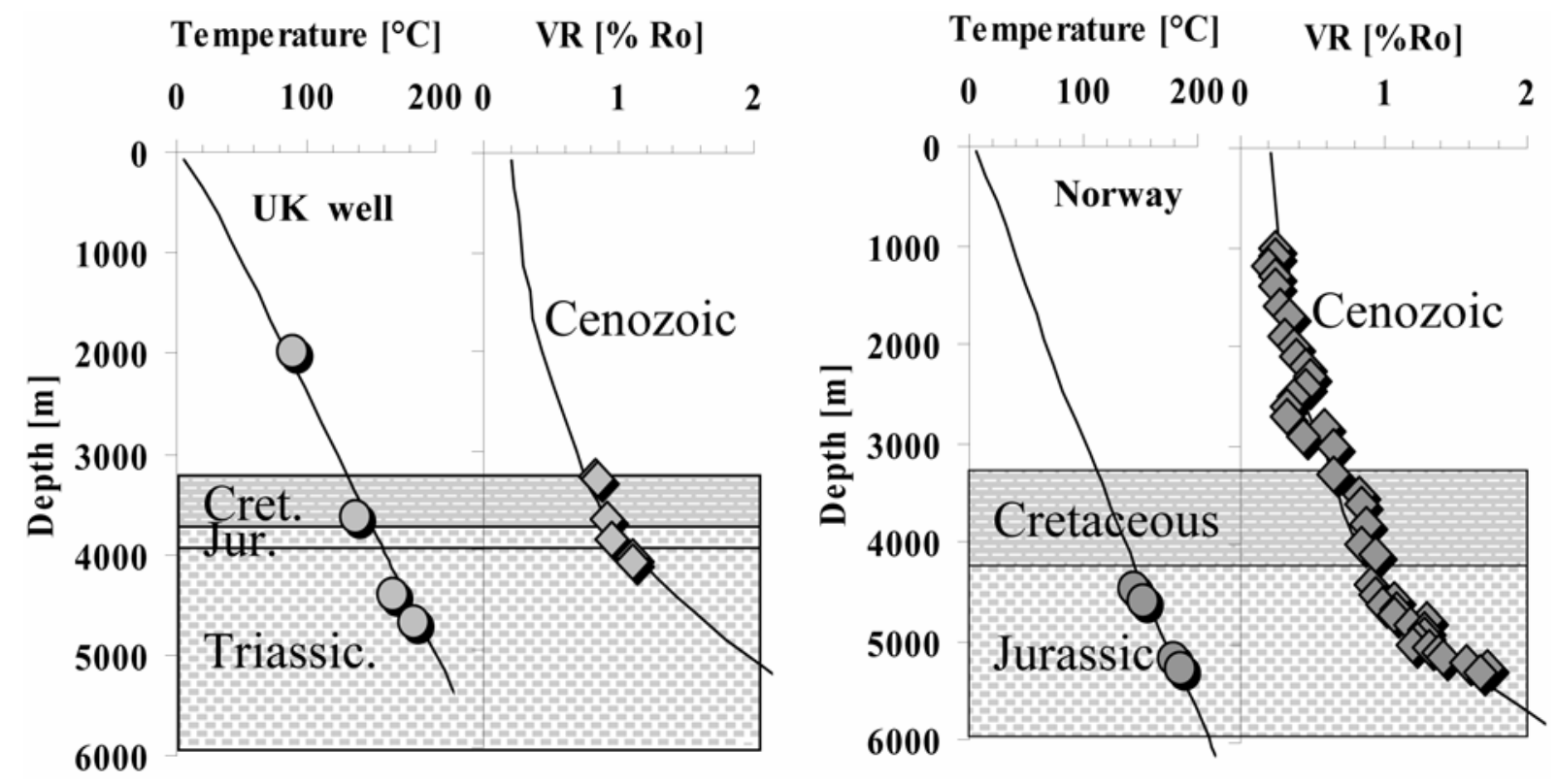

Figure 4

Temperature (solid circles) and vitrinite reflectance (solid diamonds) calibration data plotted against calculated trends (Norwegian reference well included). 


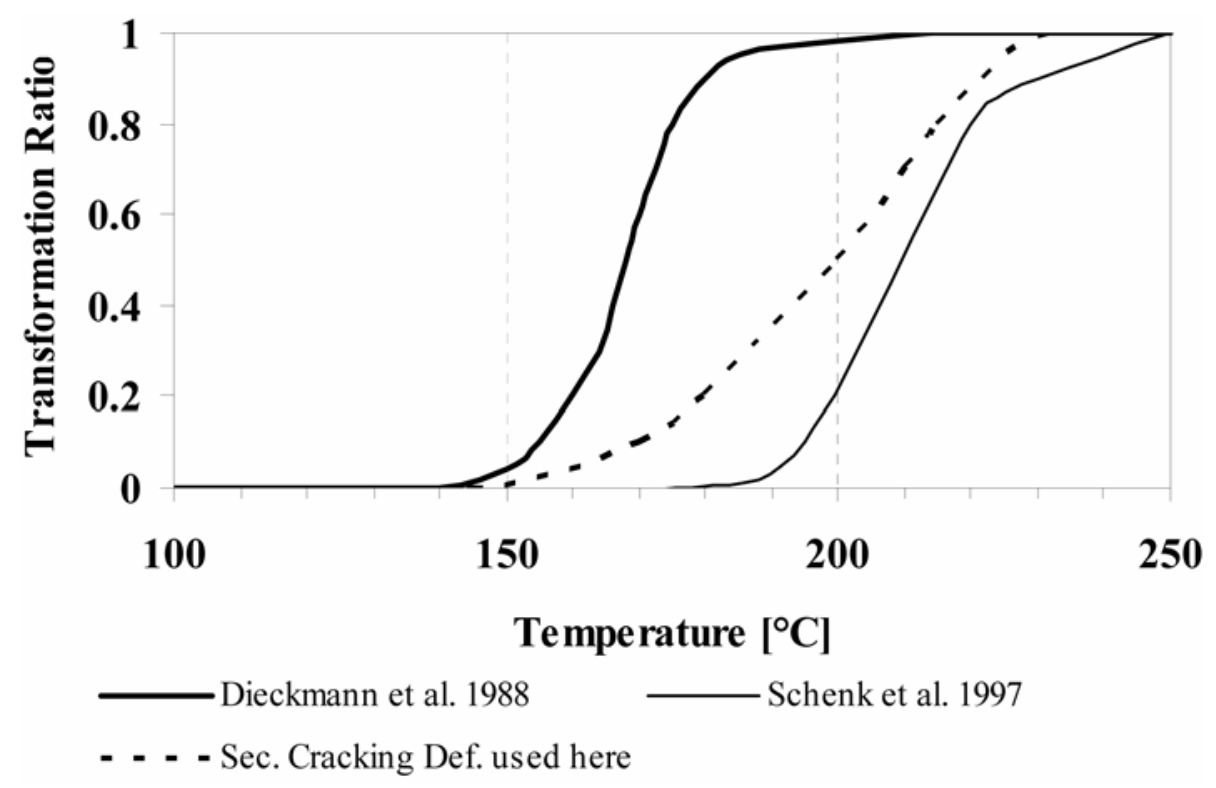

Figure 5

Cumulative evolution of the transformation ratio of oil to gas.

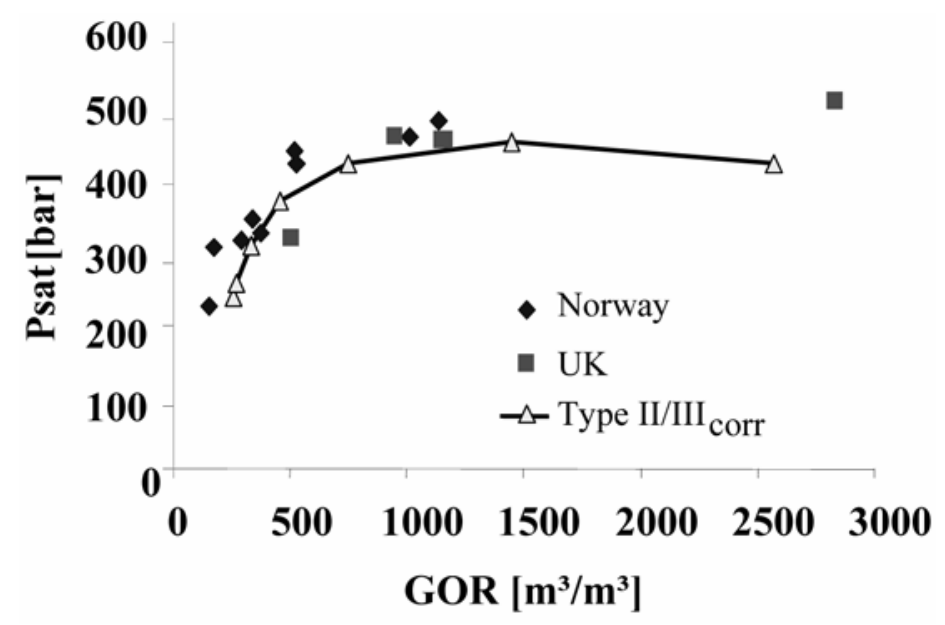

\section{Figure 6}

Model predictions (line) compared to live fluid properties (dots) of the Central Graben area. 


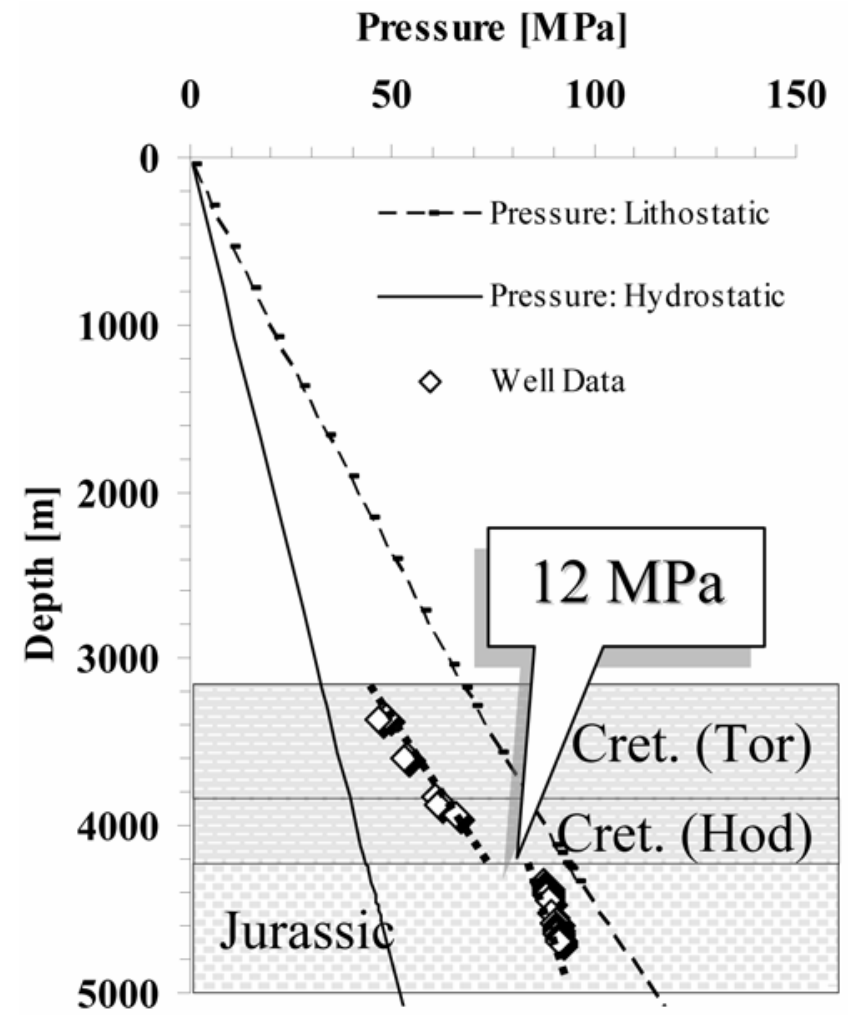

\section{Figure 7}

Pressure regime, based on predicted lithostatic and hydrostatic pressure in a Norwegian reference well, compared to calibration data. The dotted lines indicate the pore pressure trend, showing a pressure transition zone at about -4200 m TVDSS. Below that lies the overpressured Jurassic section. 


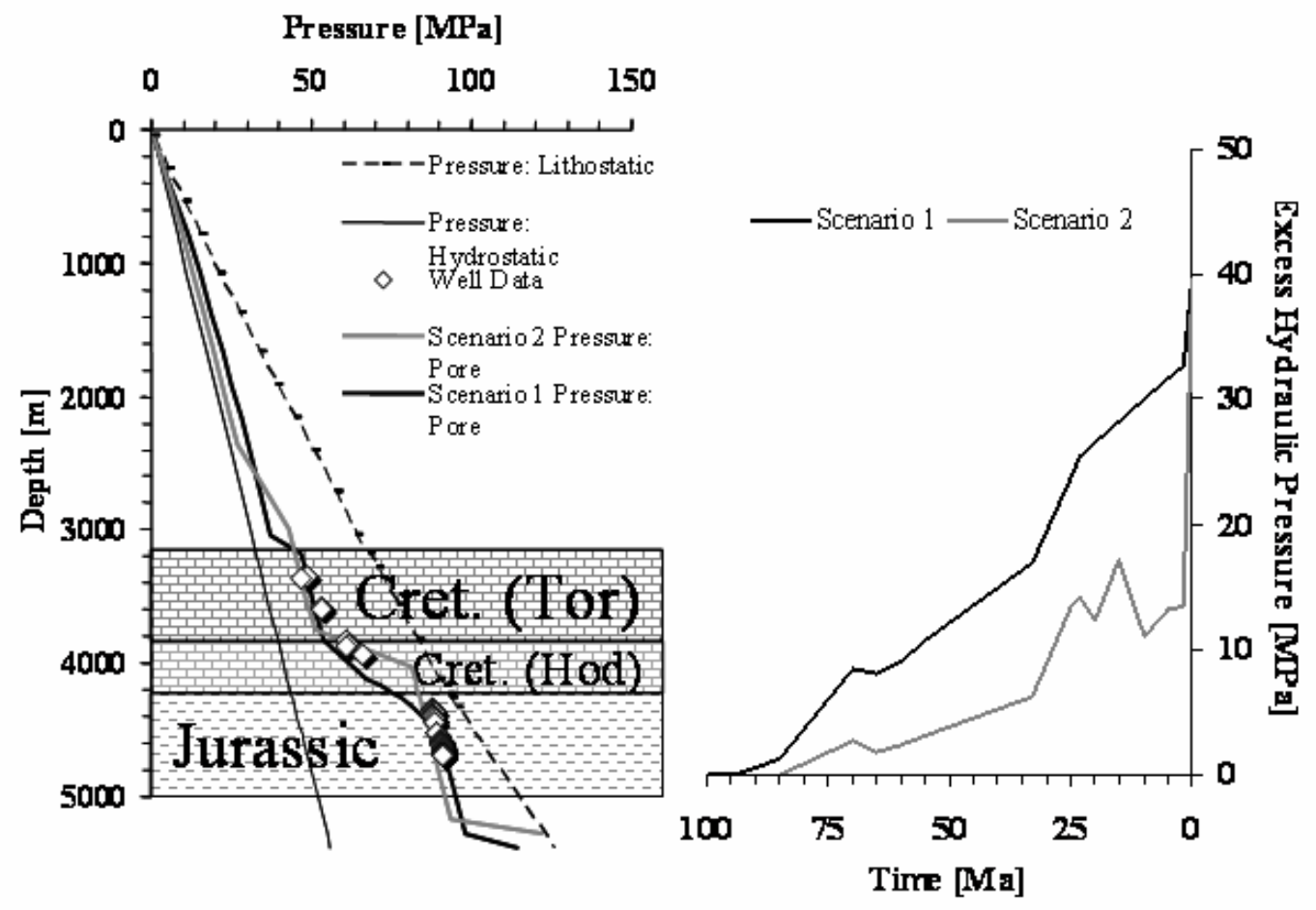

Figure 8

Pressure evolution based on the two introduced scenarios The graphs displayed in the right panel show that both mechanism lead to identical results, although their evolutionary paths are different. 


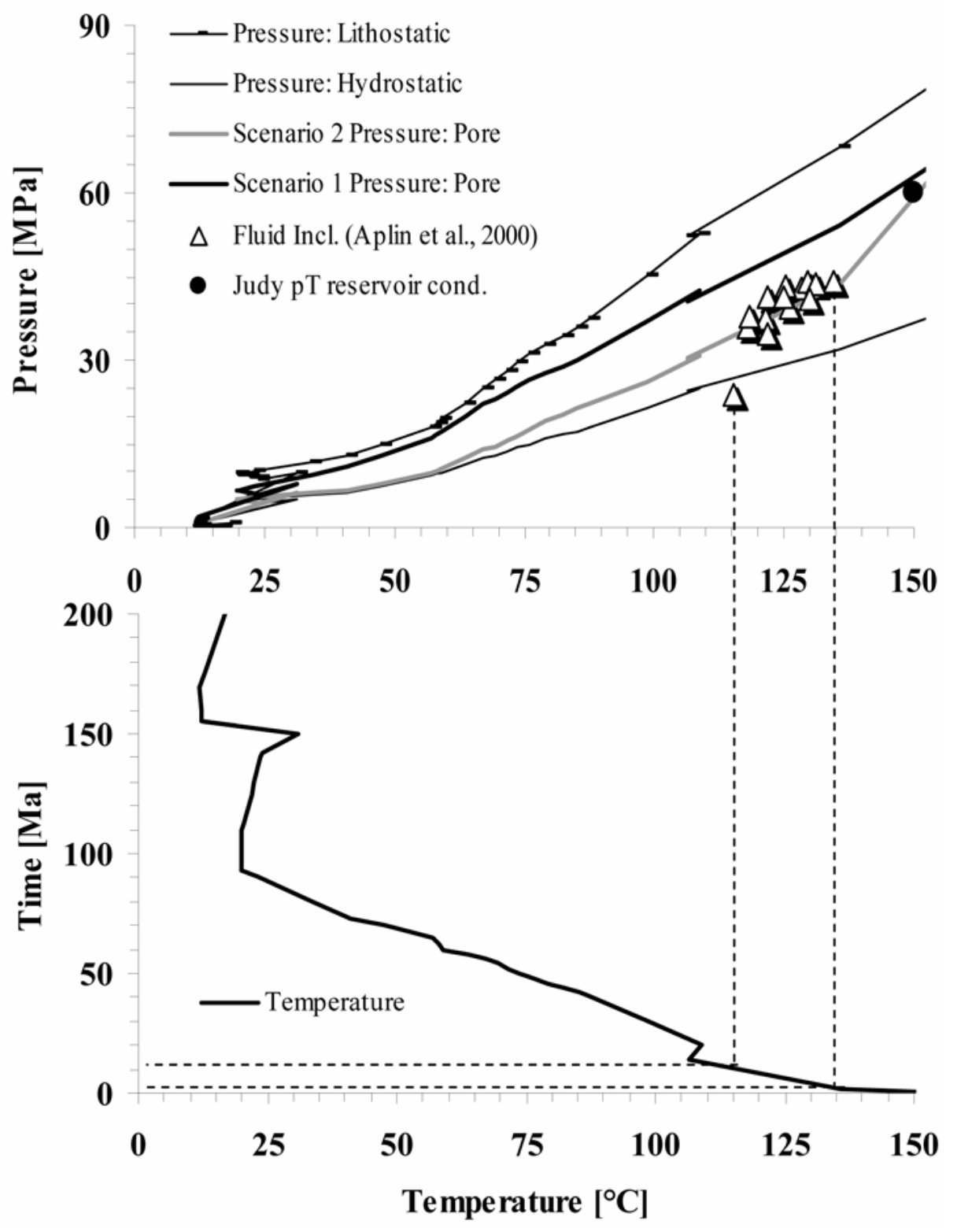

\section{Figure 9}

Pressure vs. temperature evolution through time for the Judy structure for the combined model. Included are fluid inclusion data from Aplin et al. (2000). 


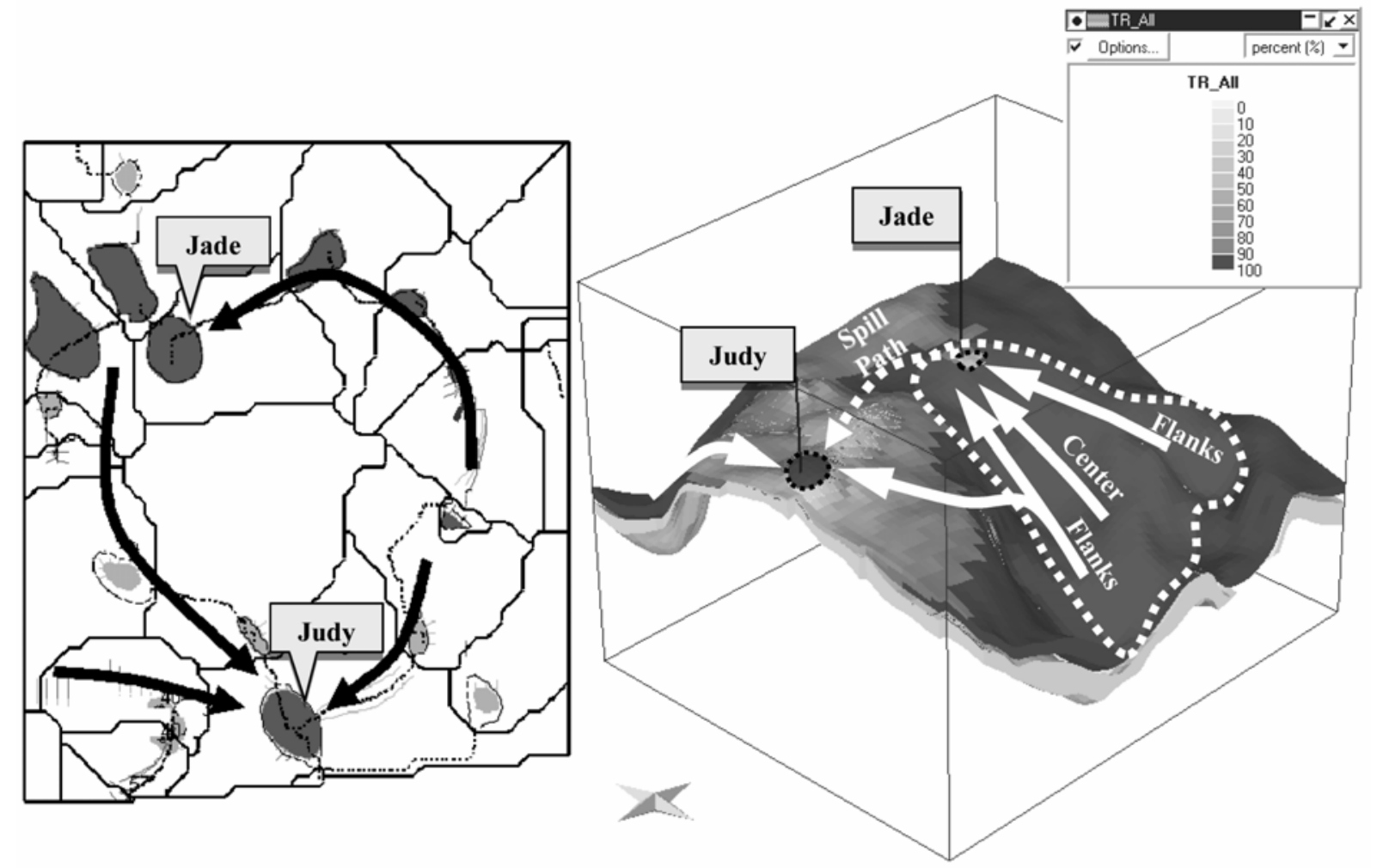

Figure 10

Left: Present day drainage areas of the Triassic Joanne Sandstone. Right: 3D view on drainage areas, including closures, hydrocarbon accumulations and migration pathways.. The map shows the topography of the Triassic Joanne sandstone (overlay is transformation ratio of the Heather Formation). The polygons are the individual drainage areas. The larger, dotted polygon shows the kitchen area for the Jade structure, white arrows show the migration paths, the dotted arrow shows the fill path to the Judy structure. 


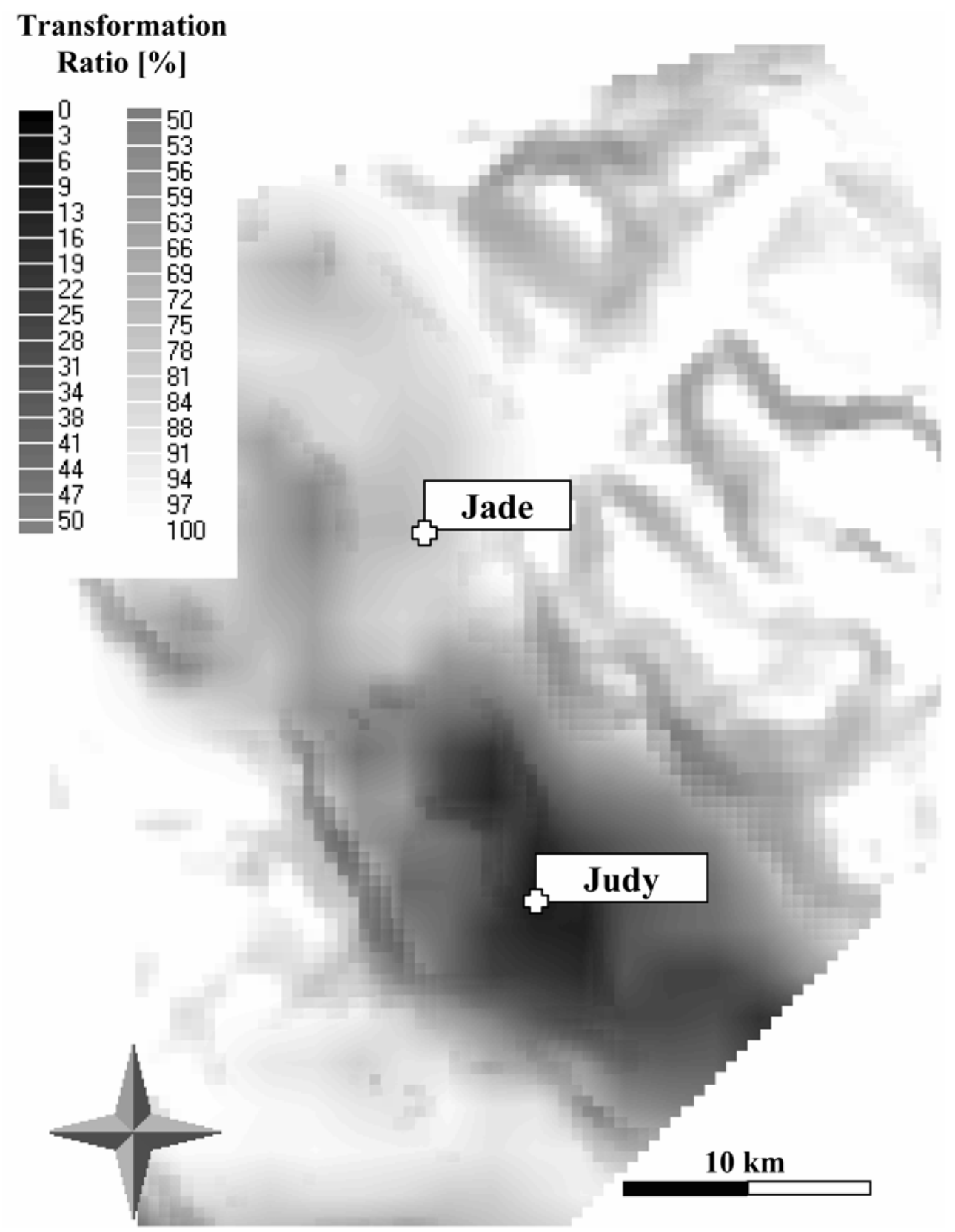

Figure 11

Present day transformation ratio of Heather formation. 

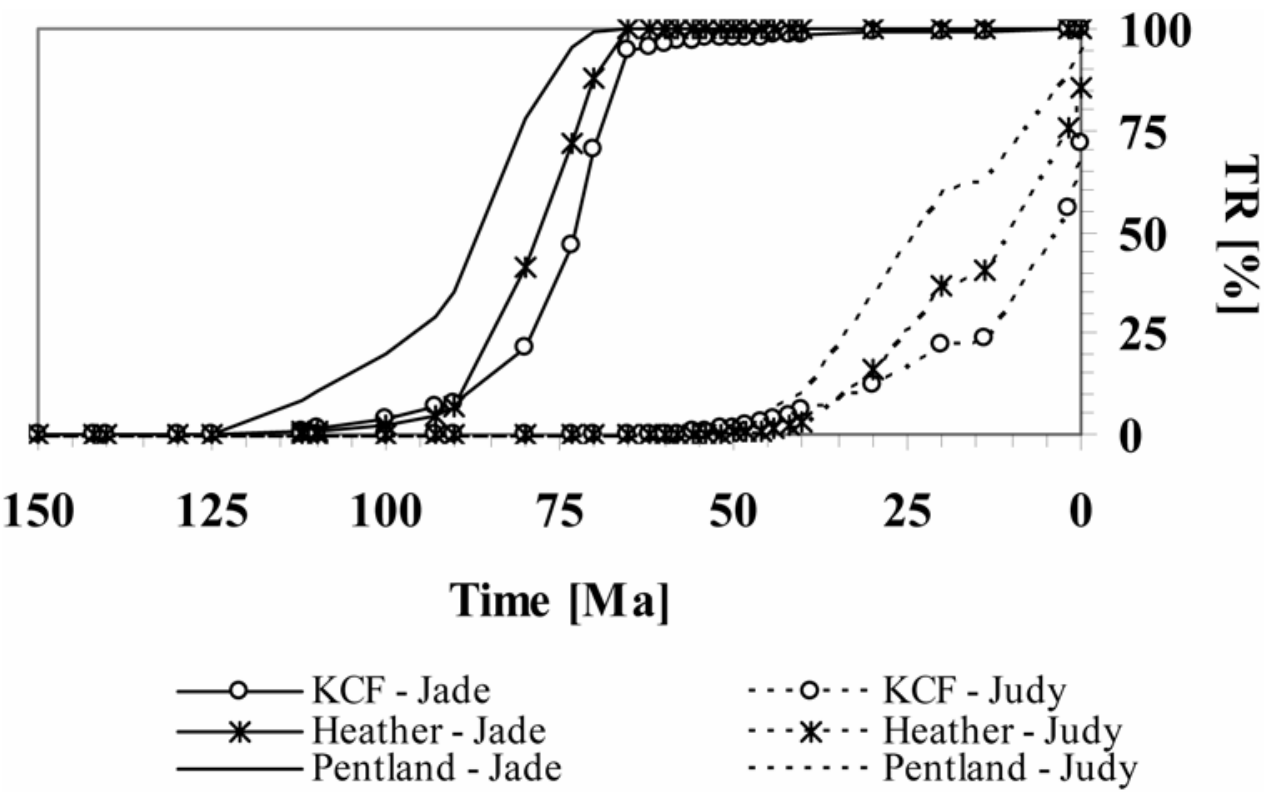

$$
\begin{aligned}
& \text { - . - - KCF - Judy } \\
& \cdots \text { - - - Heather - Judy } \\
& \text {-... Pentland - Judy }
\end{aligned}
$$

\section{Figure 12}

Transformation ratio evolution for the three source rocks (Kimmeridge Clay (KCF), Heather, Pentland) at the Judy and Jade kitchen areas (KA)).

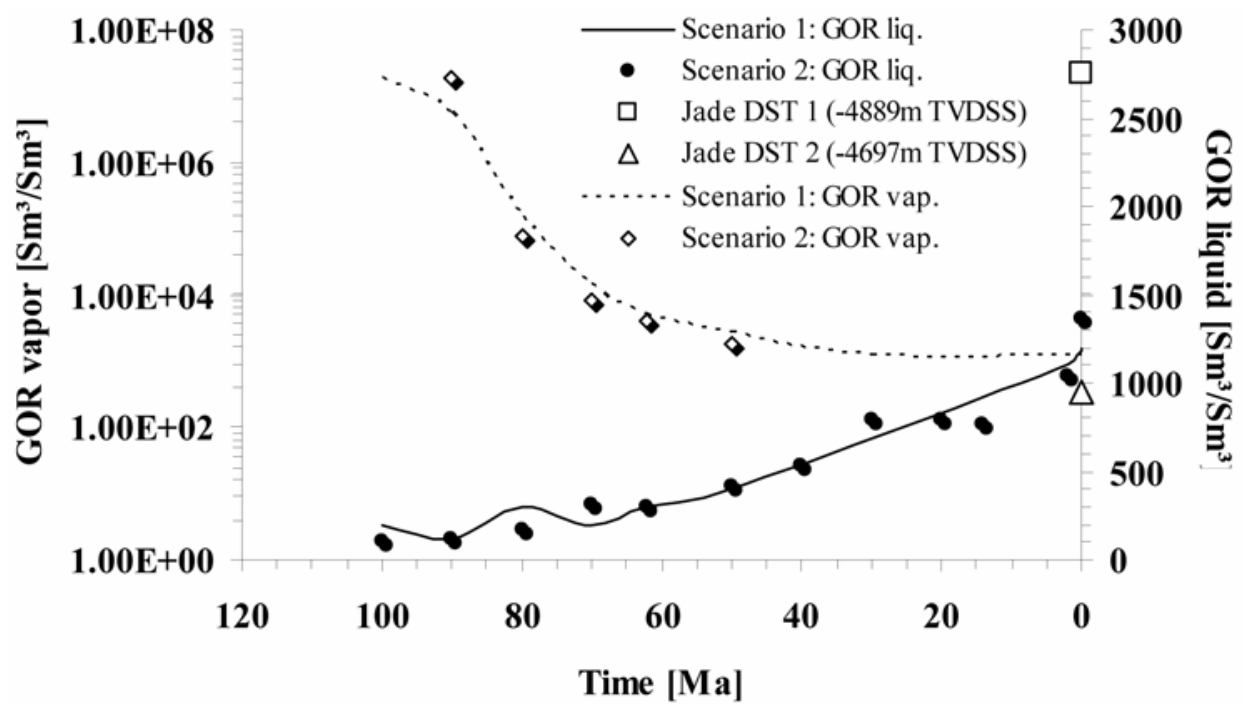

\section{Figure 13}

Development of the Jade reservoir fluid GOR, based on the combined model (Sc 2) and disequilibrium compaction alone (Sc 1). The reservoir contained in both cases modelled a two-phase system (oil and gas) until the onset of overpressure in the Late Cretaceous. 


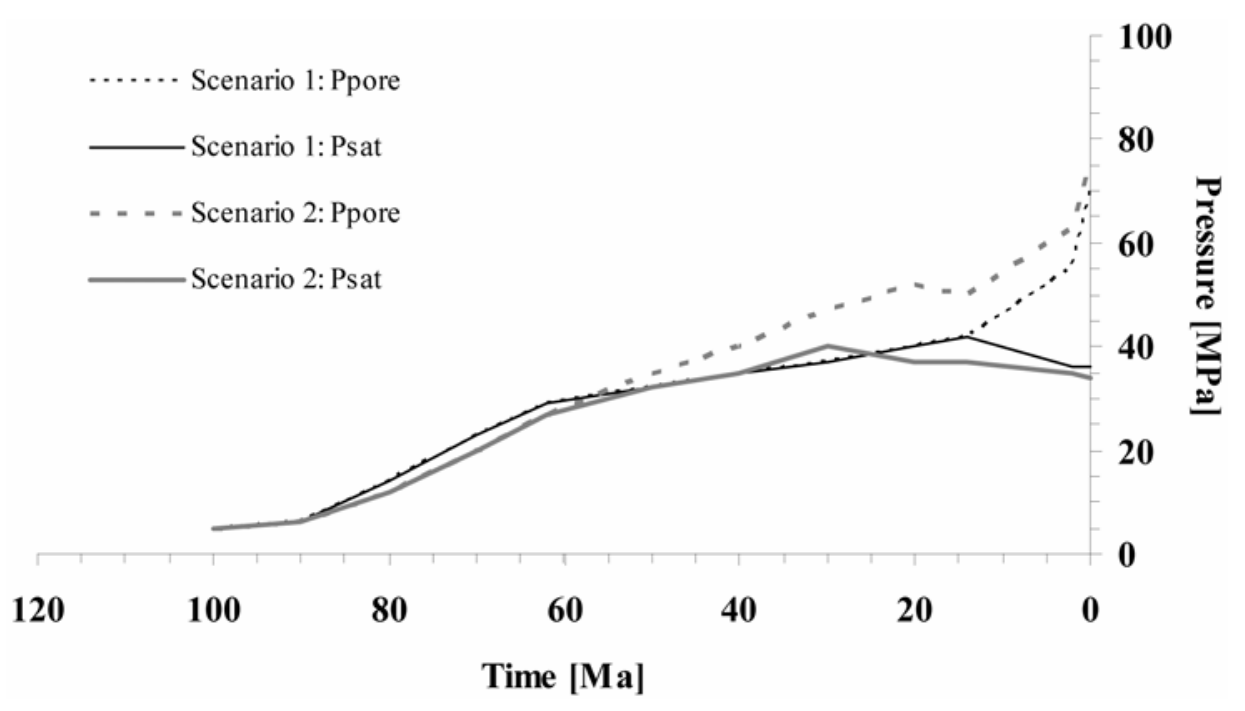

Figure 14

Development of reservoir fluid saturation (Psat) and pore pressures (Ppore) in the Jade field (both pressure scenarios).

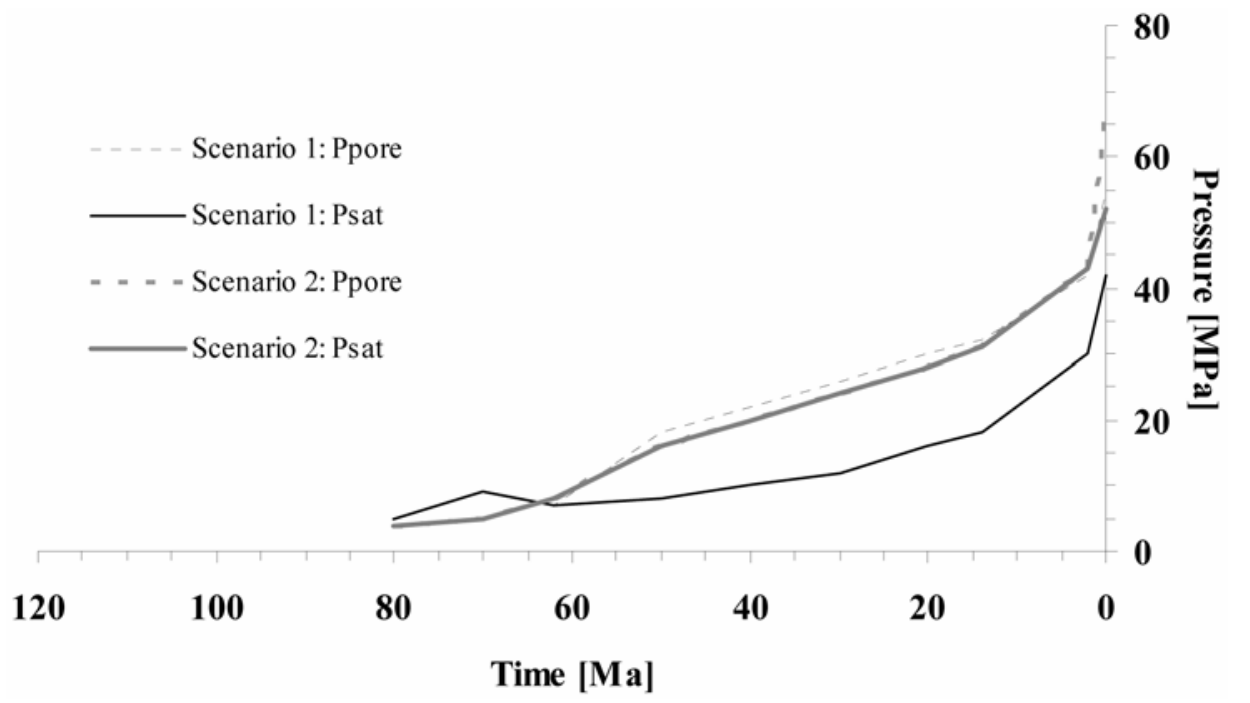

Figure 15

Development of reservoir fluid saturation (Psat) and pore pressures (PPore) in Judy field (both pressure scenarios). 


\section{Table Index}

\section{Table 1}

Activation energies (A), frequency factors (Ea) and reduction factors (describing the proportion of the compound converted, the rest is assumed to form dead carbon) used for each liquid compound.

\begin{tabular}{lllll}
\hline Compound & A [1/Ma] & Ea [kcal/mol] & $\begin{array}{l}\text { Reduction } \\
\text { Factor }\end{array}$ & $\begin{array}{l}\text { Product: } \\
\text { Methane [\%] }\end{array}$ \\
\hline C7-15 & $1 \mathrm{e} 30$ & 69 & 0.45 & 100 \\
C16-25 & $1 \mathrm{e} 30$ & 66 & 0.45 & 100 \\
$\mathrm{C} 26-35$ & $1 \mathrm{e} 30$ & 64 & 0.4 & 100 \\
$\mathrm{C} 36-45$ & $1 \mathrm{e} 30$ & 63 & 0.4 & 100 \\
$\mathrm{C} 46-55$ & $1 \mathrm{e} 30$ & 60.5 & 0.3 & 100 \\
C56-80 & $1 \mathrm{e} 30$ & 59 & 0.3 & 100 \\
\hline
\end{tabular}

Table 2

Present-day reservoir fluid data of the Jade well 30/2c-4 and the Judy well 30/7a-P9. 


\begin{tabular}{|c|c|c|c|c|}
\hline & \multirow{2}{*}{$\begin{array}{c}\text { Well } \\
\text { Sample Type }\end{array}$} & \multicolumn{2}{|c|}{ JADE 30/2c-4 } & \multirow{2}{*}{$\begin{array}{c}\text { JUDY 30/7a-P9 } \\
\text { DST }\end{array}$} \\
\hline & & DST 1 & DST 2 & \\
\hline \multirow{15}{*}{$\frac{\bar{o}}{\frac{\bar{o}}{o}}$} & $\mathbf{N}_{2}$ & 0.36 & 0.23 & 1.17 \\
\hline & $\mathrm{CO}_{2}$ & 2.56 & 2.40 & 0.77 \\
\hline & HS & $<0.01$ & $<0.01$ & $<0.01$ \\
\hline & $\mathrm{C1}$ & 71.89 & 81.82 & 80.82 \\
\hline & $\mathrm{C2}$ & 8.30 & 6.92 & 9.67 \\
\hline & $\mathrm{C3}$ & 3.52 & 2.36 & 4.25 \\
\hline & iC4 & 0.82 & 0.53 & 0.58 \\
\hline & $\mathrm{nC4}$ & 1.35 & 0.89 & 1.30 \\
\hline & iC5 & 0.53 & 0.36 & 0.29 \\
\hline & nC5 & 0.65 & 0.36 & 0.41 \\
\hline & C6 & 0.84 & 0.46 & 0.30 \\
\hline & $\mathrm{C} 7$ & 1.09 & 0.55 & - \\
\hline & $\mathrm{C} 7+$ & 9.18 & 3.67 & 0.44 \\
\hline & $\mathrm{C10+}$ & 5.90 & 2.11 & - \\
\hline & Total & 100.00 & 100.00 & 100.00 \\
\hline \multicolumn{2}{|c|}{ Depth [m TVDSS] } & -4889 & -4697 & -3408 \\
\hline \multicolumn{2}{|c|}{$\mathbf{T}_{\text {Res }} \cdot\left[{ }^{\circ} \mathbf{C}\right]$} & 193.9 & 187.8 & 149.0 \\
\hline \multicolumn{2}{|c|}{$\mathbf{P}_{\text {Res. }}[\mathrm{MPa}]$} & 85.2 & 83.9 & 60.4 \\
\hline \multirow{2}{*}{ Field } & ${ }^{\circ} \mathrm{API}$ & 46.0 & 39.9 & $40-42$ \\
\hline & $\operatorname{GOR}\left[\mathrm{Sm}^{3} / \mathrm{Sm}^{3}\right]$ & 952 & 2836 & $378-1000$ \\
\hline \multirow{2}{*}{ Mode } & ${ }^{\circ} \mathrm{API}$ & \multicolumn{2}{|c|}{51} & 44 (total) \\
\hline & $\operatorname{GOR}\left[\mathrm{Sm}^{3} / \mathrm{Sm}^{3}\right]$ & \multicolumn{2}{|c|}{1360} & 961 (total) \\
\hline
\end{tabular}

